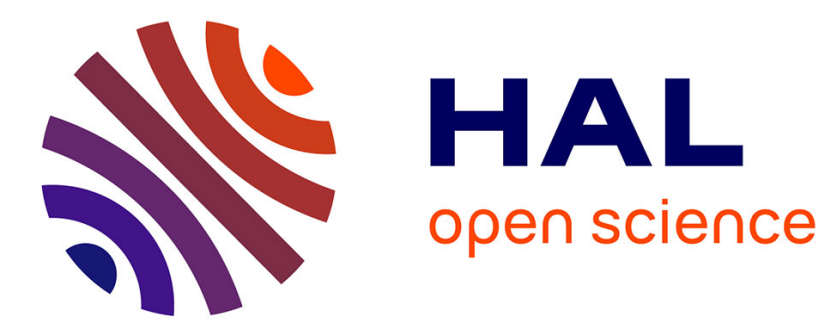

\title{
The influence of laser assistance on the machinability of the titanium alloy Ti555-3
}

Tarek Braham-Bouchnak, Guénaël Germain, Anne Morel, Jean-Lou Lebrun

\section{To cite this version:}

Tarek Braham-Bouchnak, Guénaël Germain, Anne Morel, Jean-Lou Lebrun. The influence of laser assistance on the machinability of the titanium alloy Ti555-3. International Journal of Advanced Manufacturing Technology, 2013, 68 (9-12), pp.2471-2481. 10.1007/s00170-013-4855-7 . hal-02486086

\section{HAL Id: hal-02486086 \\ https://hal.science/hal-02486086}

Submitted on 20 Feb 2020

HAL is a multi-disciplinary open access archive for the deposit and dissemination of scientific research documents, whether they are published or not. The documents may come from teaching and research institutions in France or abroad, or from public or private research centers.
L'archive ouverte pluridisciplinaire HAL, est destinée au dépôt et à la diffusion de documents scientifiques de niveau recherche, publiés ou non, émanant des établissements d'enseignement et de recherche français ou étrangers, des laboratoires publics ou privés. 


\title{
The influence of laser assistance on the machinability of the titanium alloy Ti555-3
}

\author{
T. Braham-Bouchnak • G. Germain • A. Morel • J. L. Lebrun
}

\begin{abstract}
The Ti533-3 alloy is a new titanium alloy which is starting to see increased use in the aeronautical domain to improve the durability of components and to optimize the weight/resistance ratio. This alloy is characterized by greater resistance compared to the more commonly used titanium alloys such as Ti6Al4V. However, a disadvantage of the Ti533-3 alloy is that it is very difficult to machine. In this work, the use of laser-assisted machining has been tested to improve chip formation by a thermal softening phenomenon and to improve the machining productivity of the alloy. A parametric investigation of laser assistance on the machinability of the Ti555-3 titanium alloy shows that: (1) the cutting forces can be greatly decreased if the surface temperature is high; (2) the thermal gradient induced by laser heating modifies the surface integrity in terms of strain hardening and residual stresses in the workpiece; and (3) the chip formation mechanisms are also changed, by increasing the sawteeth frequency when using laser assistance.
\end{abstract}

Keywords Laser-assisted machining · Machinability · Titanium alloys $\cdot$ Ti555-3 $\cdot$ Surface integrity $\cdot$ Cutting force

\section{Introduction}

The large-scale use of carbon fiber-reinforced plastic (CFRP) for much of the structure of modern aircraft (i.e.

\footnotetext{
T. Braham-Bouchnak $\cdot$ G. Germain $(\bowtie) \cdot$ A. Morel Arts et Métiers ParisTech, LAMPA-EA1427, 2, Bd de Ronceray, 49000 Angers, France

e-mail: guenael.germain@ensam.eu

J. L. Lebrun

ESTP_École Spéciale des Travaux Publics du bâtiment et de l'industrie, 28 avenue du Président Wilson, 947234 Cachan Cedex, France
}

fuselage and wing) has raised new issues for metallic materials. Prior to the Airbus A380, the use of titanium alloys was very limited, with their main application being restricted to the engine pylons. Recently, titanium alloys have been used to replace aluminum alloys for fuselage components. Indeed, titanium alloys have better compatibility with CFRP compared to aluminum alloys. The percentage of titanium alloys, in terms of mass, has almost doubled in the Airbus A380 compared to the A350. The titanium alloy components are often very elaborate and require substantial machining operations. However, it is estimated that the difference in productivity between the machining of an aluminum alloy and that of a titanium alloy can be up to 30. This value gives an idea of the difficulties confronted by machinists required to manufacture titanium components and the resulting additional costs. In addition, new more resistant titanium alloys, such as the Ti555-3 alloy, have appeared on the market to improve the resistance of components and to optimize the weight/resistance ratio. These new materials have even lower machinability than more common titanium alloys such as the Ti6Al4V alloy [1]. The industrial objective is to increase the productivity of the machining of titanium alloys and reduce costs.

The difficulties encountered in the machining of the Ti555-3 alloy encourage the investigation of new processes to improve its machinability. Assisted machining can have an advantage over conventional machining via the addition of a new energy source that influences the cutting zone. This energy source can take different forms, such as highpressure water jet-assisted machining [2], cryogenic assistance [3], and high-temperature assistance via either induction heating [4] or by laser [5].

After a review of the state of the art concerning the machining of the Ti555-3 alloy and the advantages and limitations of assisted machining of this alloy, this investigation focuses on laser-assisted machining (LAM) and its 
effect in terms of cutting forces, chip morphology, roughness and, above all, surface integrity of the workpiece. The results will be analyzed and discussed.

\section{State of the art of the machining of the Ti555-3 alloy}

The difficulties associated with the machining of titanium alloys are well known in the literature and are related to their physical, chemical, and thermo-mechanical properties [6]. These materials have low thermal conductivity, which limits heat transfer and causes strong localization of the cutting temperature $\left(>1,000{ }^{\circ} \mathrm{C}\right)$ in the zone at the tool tip. These alloys also exhibit a high chemical affinity with most components used in the surface treatment of cutting tools, leading to premature tool wear. The chips formed during cutting have a greater tendency to weld to the cutting tool, which can accelerate the phenomenon of wear. Titanium alloys also have a lower elastic modulus, which can generate vibrational effects during machining [7]. Finally, they retain high hardness and resistance at high temperatures, which leads to high cutting forces. One avenue for improving the machinability of these materials is therefore to modify the cutting tool (coated cemented carbides, ceramic tools, cubic boron nitrides, and solid lubricant coating) [8]. To the author's knowledge, this type of work has not been conducted on the Ti555-3 titanium alloy. Data relative to the degradation of some cutting tools are, however, available in the literature. For example, Arrazola et al. [1] have focused on this in a comparative study of the mechanisms of tool wear during machining of the Ti555-3 and Ti6Al4V alloys. With an uncoated cemented carbide tool (grade K15 micrograin), these authors evaluate a maximum cutting speed beyond which a small increase in the cutting speed causes severe wear of the tool for $15 \mathrm{~min}$ of machining. They quantify, for an advance of $0.1 \mathrm{~mm} / \mathrm{rev}$ and a cutting depth of $2 \mathrm{~mm}$, a maximum cutting speed of $80 \mathrm{~m} / \mathrm{min}$ for the Ti6Al4V alloy and $45 \mathrm{~m} / \mathrm{min}$ for the Ti555-3 alloy. These authors make the link between the maximum cutting speed and the machining rate, and determine that the machinability rate of the Ti6Al4V alloy is $56 \%$ higher than that of the Ti555-3 alloy. Wagner et al. [9] worked on optimizing the rake angle and edge preparation for machining of the Ti555-3 alloy. They find that the best choice is to use a tool with a sharp edge, a rake angle of $20^{\circ}$ and a feed value superior to edge preparation.

Another way of improving the machinability of titanium alloys is through the use of assisted machining. In the case of the Ti555-3 alloy, two investigation paths have been followed. The first was to use high-pressure water jet assistance to break the chips and reduce the temperatures close to the tool tip. Braham-Bouchnak [10] conducted a study of the chip morphology for tests done on the Ti555-3 alloy using dry lubrication and both low- and high-pressure water jet assistance with pressures between 50 and 300 bars. He determined that the chips were fragmented in an optimal manner at a pressure of 200 bars. At this pressure, the white zones formed in this alloy in the secondary shear zone (i.e. due to friction at the tool/chip interface) are finer than those formed during dry machining. The reduction of the width of the white zones is attributed to forced cooling by the highpressure water jet and by changes in the frictional conditions at the chip/tool interface under the action of the jet. For a cutting speed of $50 \mathrm{~m} / \mathrm{min}$, an advance of $0.15 \mathrm{~mm} / \mathrm{rev}$ and a cutting depth of $0.5 \mathrm{~mm}$, Braham-Bouchnak evaluated the life of the tool to be $8 \mathrm{~min} 45 \mathrm{~s}$ for dry machining and 22 min with water jet assistance at a pressure of 200 bars. Moreover, the cutting forces are reduced by approximately $23 \%$.

A second possible way to improve the machinability of the Ti555-3 alloy is to increase the initial temperature of the material to reduce the mechanical properties and in particular the plastic flow stress. This thermal softening phenomenon can decrease the specific cutting force Kc [11]. To increase the initial temperature of the material, Baili et al. [4] choose induction-assisted hot machining, designed to maintain a constant temperature of the workpiece during turning. They found that the decrease in specific cutting force $\mathrm{Kc}$ is significant only for temperatures above $500{ }^{\circ}$ C. This reduction ranges from 13 to $34 \%$ in the temperature range from 500 to $750{ }^{\circ} \mathrm{C}$. At the same time, the increase in temperature leads to higher thermal loads seen by the tool, reducing its lifespan. This reduction is not quantified, but a modification of the tool degradation mode is observed. At $750{ }^{\circ} \mathrm{C}$, a built-up edge grows on the entire cutting width. This is attributed to very high temperatures at the tool/chip interface and a lower contact pressure in this area. Baili [4] characterized the surface integrity of the machined Ti555-3 alloy with respect to hardness and micro-roughness. They found that there was a slight increase in micro-Vickers hardness of the workpiece surface, of about $40 \mathrm{Hv}$ from ambient temperature to $750{ }^{\circ} \mathrm{C}$. The roughness measurements are also quite scattered. However, Baili quantifies a decrease in roughness as a function of temperature, which passes from a roughness value of $R_{\mathrm{a}}=1.6 \mu \mathrm{m}$ at $25{ }^{\circ} \mathrm{C}$ to $R_{\mathrm{a}}=0.8 \mu \mathrm{m}$ for temperatures above $200{ }^{\circ} \mathrm{C}$. This evolution is attributed to the decrease in ductility at higher temperatures and to the reduction in the cutting forces that result notably in more malleable chips that are more easily evacuated and in less vibration during cutting [7].

Increasing the initial temperature of the material can also be done through more local heating techniques that affect only the volume of material to be removed. The heat source could be a plasma arc [12]; however, the heating density that can be obtained by laser heating is much greater. The laser 
spot size is also smaller and more controllable [7], as is the heat-affected depth [13]. However, to the authors' knowledge, there are no publications concerning the effects of laser-assisted machining of the Ti555-3 titanium alloy.

\section{Material and experimental set-up}

\subsection{Material}

The Ti555-3 titanium alloy is a quasi-beta alloy developed for the construction of large components subjected to high mechanical loads such as aircraft landing gear. It is a variant of the Russian alloy VT22 (Ti-5Al-5V-5Mo-1Cr-1Fe) and an alternative to the Ti-10Al-2 $\mathrm{V}-3 \mathrm{Mb}$ alloy. Its mechanical properties are excellent and are summarized in Table 1. Table 2 shows the chemical composition of the alloy.

The microstructure of the Ti555-3 alloy is composed of $\alpha$ particles in the form of nodules, in a predominately $\beta$ matrix, as shown in Fig. 1. The size of these nodules varies between approximately 1 and $10 \mu \mathrm{m}$. There are also intragranular $\alpha$ particles of nanoscopic dimension called the secondary alpha phase $\alpha_{\mathrm{s}}$, created by the transformation of the $\beta$ phase during tempering (Fig. 2).

\subsection{Experimental set-up}

Laser-assisted machining results in localized heating of the workpiece, upstream of the tool, with very high power densities over a very small area. This is contrary to techniques using global heating of the workpiece [7]. The laser beam, of diameter $0.8 \mathrm{~mm}$, heats the workpiece a few millimeters in front of the tool, thus lowering the flow stress of the material in order to improve its machinability [14].

The tests were performed on a lathe specially developed by the company Realmeca ${ }^{\circledR}$ for laser-assisted machining. This RT-5 lathe, for hard turning, has been adapted to include a permanent structure allowing for the five-axis control of the laser-focusing head in the lathe enclosure. It

Table 1 Mechanical and thermal properties of the Ti555-3 alloy

\begin{tabular}{lll}
\hline Property & Value & Units \\
\hline Density & 4.65 & $\mathrm{~g} \mathrm{~cm}^{-3}$ \\
Hardness & 354 & - \\
Yield strength & 1,174 & $\mathrm{MPa}$ \\
Ultimate tensile strength & 1,236 & $\mathrm{MPa}$ \\
Percent elongation at failure & $6 \%$ & - \\
Young's modulus & 110 & $\mathrm{GPa}$ \\
Poisson's coefficient & 0.31 & - \\
T $\beta$ phase change temperature & 845 & ${ }^{\circ} \mathrm{C}$ \\
\hline
\end{tabular}

is connected by optical fiber to a continuous $\mathrm{Nd}$ :YAG laser source with a maximum power of $2.5 \mathrm{~kW}$. The lathe is also fitted with a Kistler ${ }^{\circledR}$ dynamometer for measuring the three components of the cutting force.

\subsection{Test conditions}

There are a large number of experimental parameters to be determined in laser-assisted machining because both the parameters specific to machining (cutting speed $V_{\mathrm{C}}$, feed $f$, depth of cut $a_{\mathrm{p}} \ldots$ ) and the parameters specific to the laser (power, angle of inclination, laser position...) must be taken into account. The tests are performed under conditions of longitudinal turning with a PCLNL 2525 M12 tool and a grade S05F, CNMG 120408 insert from Sandvik ${ }^{\circledR}$. Germain et al. (2007) showed that for a Ti6Al4V alloy, the ideal position of the laser spot, for which the cutting forces are lowest and the surface integrity is improved, is $5 \mathrm{~mm}$ in front of the tool. He also determined that the angle of incidence of the laser beam does not influence the results as long as it is less than $40^{\circ}$. In order to avoid collisions between the tool holder and the laser-focusing head, the angle of incidence is chosen to be equal to $20^{\circ}$ relative to the direction perpendicular to the workpiece. As the thermal conductivity of the Ti555-3 alloy is similar to that of the Ti6Al4V alloy [9], the laser spot is positioned $5 \mathrm{~mm}$ from the tool. The remaining input parameters are cutting speed, the feed, and the cutting depth. Each test is performed without laser assistance and with laser assistance at 500and 1,500-W laser power. Table 3 summarizes the chosen test configurations.

The tool inserts were changed in each test so that the results are not affected by wear. For each test, the three components of the cutting force were measured as well as the surface roughness. The residual stresses were also analyzed, by the x-ray diffraction technique, for certain tests.

To analyze the residual stress fields in the workpiece after machining, a PROTO portable x-ray diffractometer was used to determine the diffraction peaks and automatically process the results. The system is based on the $\sin ^{2} \psi$ method. The principle is to use the variation of the atomic spacing as strain gauge [15].

The parameters associated with the residual stress analyses done in this work are presented in Table 4. The stresses are determined in the axial and circumferential directions of the workpiece. The uncertainty of each measurement point is estimated to be $\pm 50 \mathrm{MPa}$. The analysis of the residual stress evolution as a function of depth was conducted by electrochemically removing a layer of material between each measurement. The stress profiles are analyzed in conjunction with the diffraction peak widths. These values give an indication of the level of strain hardening of the workpiece. 
Table 2 Chemical composition of the Ti555-3 alloy

\begin{tabular}{lllllllll}
\hline Al & V & Cr & Mo & Fe & H & C & O & N \\
\hline 4.91 & 5.25 & 2.98 & 5.22 & 0.35 & 0.001 & 0.008 & 0.135 & 0.006 \\
\hline
\end{tabular}

\section{Results}

4.1 Influence of laser-assisted machining on the cutting forces

The tests are based on tool-material pair [16] to determine the evolution of the specific cutting pressure in both conventional and laser-assisted machining. The feed $f$ is fixed at $0.2 \mathrm{~mm} / \mathrm{rev}$ and the depth of cut $a_{\mathrm{p}}$ at $0.5 \mathrm{~mm}$. The three components of the cutting forces are measured during machining by means of a Kistler ${ }^{\circledR}$ dynamometer. As the three components of the cutting force have similar evolutions, only the tangential cutting force will be discussed below.

The results, summarized in Fig. 3, show that the specific pressure decreases as cutting speed $V_{\mathrm{c}}$ increases. Arrazola et al. [17] found this effect in the Ti555-3 alloy and attributed this to the decrease of the chip thickness and lowering of the material flow stress. Moreover, the specific cutting pressure decreases with the laser power. This is related to the fact that an increase in temperature reduces the flow stress of the material. For low cutting speeds, for example, $20 \mathrm{~m} / \mathrm{min}$, the specific pressure during dry cutting is of the order of $6,800 \mathrm{~N} / \mathrm{mm}^{2}$ and decreases to $4,450 \mathrm{~N} / \mathrm{mm}^{2}$ for a laser power of $1,500 \mathrm{~W}$, which corresponds to a decrease of $35 \%$. For higher speeds, the influence of the laser power is decreased. For $V_{\mathrm{c}}=90 \mathrm{~m} / \mathrm{min}$, the specific pressure increases from $4,300 \mathrm{~N} / \mathrm{mm}^{2}$ for conventional machining to $3,450 \mathrm{~N} / \mathrm{mm}^{2}$ for laser assistance with a power of $1,500 \mathrm{~W}$. This corresponds to a decrease of only $19 \%$. This decrease in the effectiveness of laser assistance at increased cutting speed can be easily explained. Indeed, if the displacement speed of the laser beam increases, the heating time at a given point on the surface is lower. This leads to a lower temperature increase. The laser heating time is lower when the cutting speed increases, which decreases the depth of material heated by conductivity. Therefore, increasing the cutting speed leads to a smaller heated zone depth and lower temperatures, which significantly reduces the efficiency of laser assistance.

In addition, it is found that the minimum cutting speed $\left(V_{\mathrm{Cmin}}\right)$ increases with increasing laser power. $V_{\mathrm{Cmin}}$ is evaluated to be $50 \mathrm{~m} / \mathrm{min}$ for conventional machining, which is consistent with results found by Arrazola for the same alloy [1]. A laser power assistance does not significantly affect $V_{\text {Cmin. }}$.

The influence of the feed and the cutting depth were also studied for a cutting speed of $50 \mathrm{~mm} / \mathrm{min}$. Figure 4 shows that with increasing cutting depth, the effectiveness of the assistance is reduced. In fact, for large cutting depths, the depth is not sufficiently heated to observe a significant decrease in the tangential cutting force. For a cutting depth of $0.1 \mathrm{~mm}$, a feed of $0.15 \mathrm{~mm} / \mathrm{rev}$ and a laser power of $1,500 \mathrm{~W}$, the tangential cutting force decreases from $210 \mathrm{~N}$ without assistance to $90 \mathrm{~N}$ with laser assistance (i.e. a decrease of $57 \%$ ). However, for a cutting depth of $1 \mathrm{~mm}$, the force only decreases from 502 to $475 \mathrm{~N}$, which corresponds to a decrease of only $5 \%$. Additional thermal measurements done using a CCD-PIR camera on the surface of a workpiece heated by laser (without cutting) were used to determine that the surface temperature is approximately $800{ }^{\circ} \mathrm{C}$ for a laser power of $1,500 \mathrm{~W}$ [10]. This temperature decreases very rapidly with depth [18]. Laser assistance is therefore effective only if the cutting depth is low.

It can therefore be estimated that for a finishing operation with laser assistance of $1,500 \mathrm{~W}$ and a cutting depth of $0.1 \mathrm{~mm}$, the material is machined at a temperature of about
Fig. 1 Microstructure of the Ti555-3 alloy

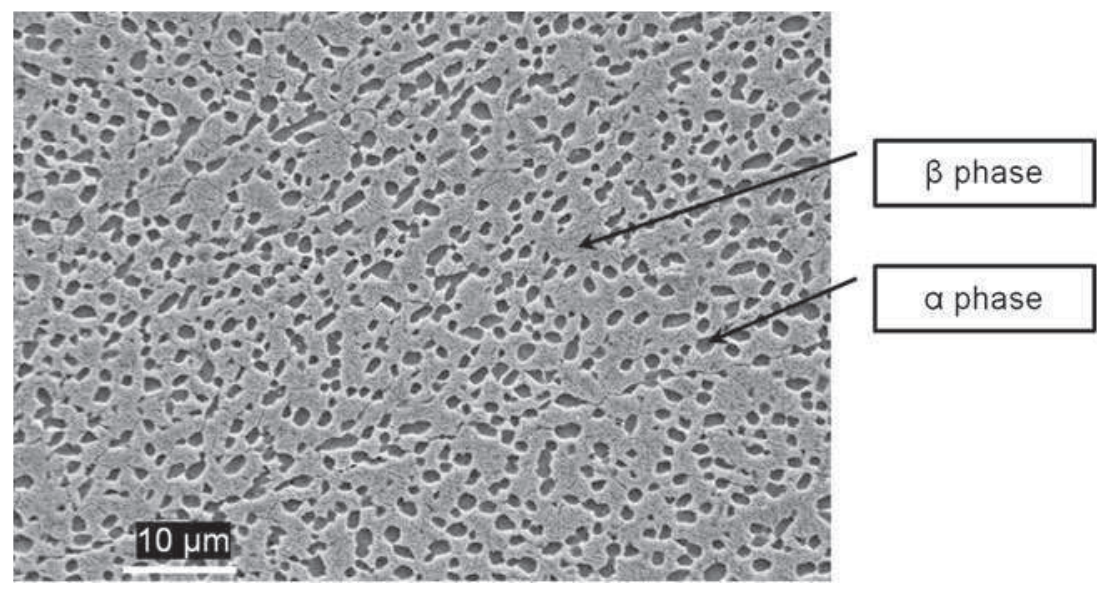




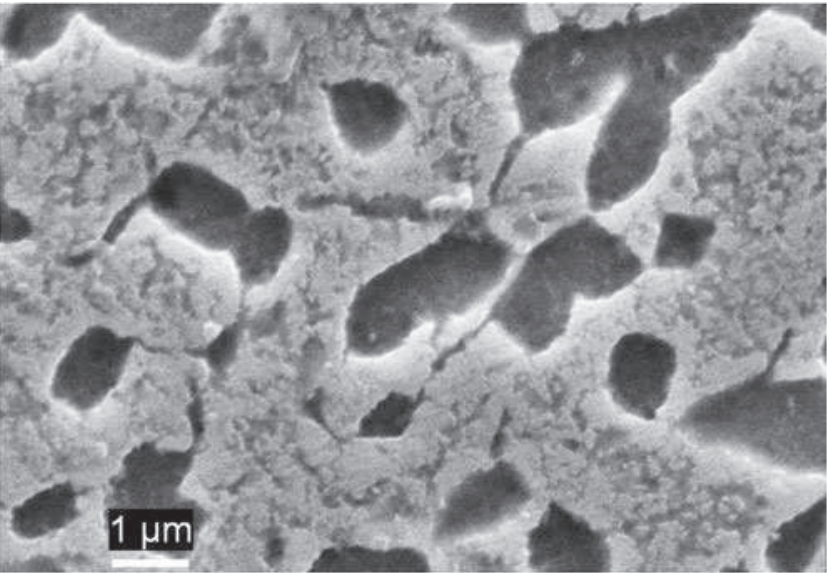

Fig. 2 Detailed view of the microstructure of the Ti555-3 alloy

$750{ }^{\circ} \mathrm{C}$ which causes a reduction of the cutting force of approximately $57 \%$. For a roughing operation, the work of Baili et al. [4] on the effect of assistance by induction heating, for the Ti555-3 alloy, was done for a much larger cutting depth $(3 \mathrm{~mm})$ as the workpiece was maintained at a uniform temperature. These authors observed a decrease in the tangential cutting force of $34 \%$ when the workpiece temperature increases from ambient to $750{ }^{\circ} \mathrm{C}$. This value is significantly lower than the results obtained in this work for a cutting depth of $0.1 \mathrm{~mm}$.

Likewise, the effect of the feed can be quantified (Fig. 4). With increasing feed, the effectiveness of laser assistance decreases. However, this decrease is significantly less than that observed for the cutting depth. Indeed, conventional machining tests and 1,500-W laser-assisted machining tests performed with a cutting depth of $0.3 \mathrm{~mm}$ and a cutting speed of $50 \mathrm{~m} / \mathrm{min}$ show a decrease in the tangential cutting force from 293 to $152 \mathrm{~N}$ (i.e. $48 \%$ reduction) for a feed of $0.1 \mathrm{~mm} / \mathrm{rev}$ and 479 to $406 \mathrm{~N}$ (i.e. $15 \%$ reduction) for a feed of $0.3 \mathrm{~mm} / \mathrm{rev}$. The reduction in cutting force is lower with a high feed because there is less preheating due to the laser. Indeed, for a feed of $0.1 \mathrm{~mm} / \mathrm{rev}$, the material is heated during eight rotations before being machined, while for a feed of $0.3 \mathrm{~mm} / \mathrm{rev}$, the material is heated for just three rotations. This reduction is nevertheless significant because

Table 3 Experimental conditions chosen for the laser-assisted machining tests

\begin{tabular}{|c|c|c|c|c|c|c|}
\hline \multirow[t]{2}{*}{$V_{\mathrm{c}}(\mathrm{m} / \mathrm{min}$} & & \multicolumn{5}{|c|}{$f(\mathrm{~mm} / \mathrm{tr})$} \\
\hline & & 0.1 & 0.15 & 0.2 & 0.25 & 0.3 \\
\hline \multirow[t]{5}{*}{$a_{\mathrm{p}}(\mathrm{mm})$} & 0.1 & \multirow[t]{5}{*}{50} & 50 & 50 & \multirow[t]{5}{*}{50} & \multirow[t]{5}{*}{50} \\
\hline & 0.3 & & 50 & 50 & & \\
\hline & 0.5 & & 50 and 100 & 10 to 100 & & \\
\hline & 0.7 & & 50 & 50 & & \\
\hline & 1 & & 50 & 50 & & \\
\hline
\end{tabular}

Table 4 X-ray diffraction parameters

\begin{tabular}{llll}
\hline Bragg angle & Diffraction plane & Radiation & Collimator diameter \\
\hline $139.6^{\circ}$ & {$[213]$} & $\mathrm{CuK} \alpha$ & $2 \mathrm{~mm}$ \\
\hline
\end{tabular}

the laser spot, of diameter $0.8 \mathrm{~mm}$, heats the whole width of the machined zone even for a feed of $0.3 \mathrm{~mm} / \mathrm{rev}$. These results are consistent with those found by Lesourd [19] for the Ti6Al4V titanium alloy. For this material, there is a decrease in cutting force as a function of the laser power of up to $45 \%$ with a feed of $0.1 \mathrm{~mm} / \mathrm{rev}$. The decrease drops to $7 \%$ when the feed is $0.4 \mathrm{~mm} / \mathrm{rev}$.

Laser assistance can greatly affect the cutting force; however, increasing the cutting speed, the feed and/or the cutting depth results in a decrease of its influence. Indeed, for high cutting speeds, advances, and/or cutting depths, the material is less heated. The resulting thermal softening is less significant. These results are consistent with those found in the literature for other alloys, as Sun et al. [5] on a commercially pure titanium or Rajagopal et al. [20] on a Ti6Al4V alloy.

4.2 Influence of laser-assisted machining on the surface integrity

The surface integrity was studied by observing the evolution of the surface roughness and the residual stresses as a function of laser power for different test configurations.

\subsubsection{Surface roughness}

Roughness measurements were performed on machined surfaces to analyze the effect of different cutting parameters and the laser power on the surface of the workpiece. The roughness values reported in this study are an average of three measurements taken perpendicular to the machining grooves on two different places of the machined surface. The measurements were performed using a Hommel Tester

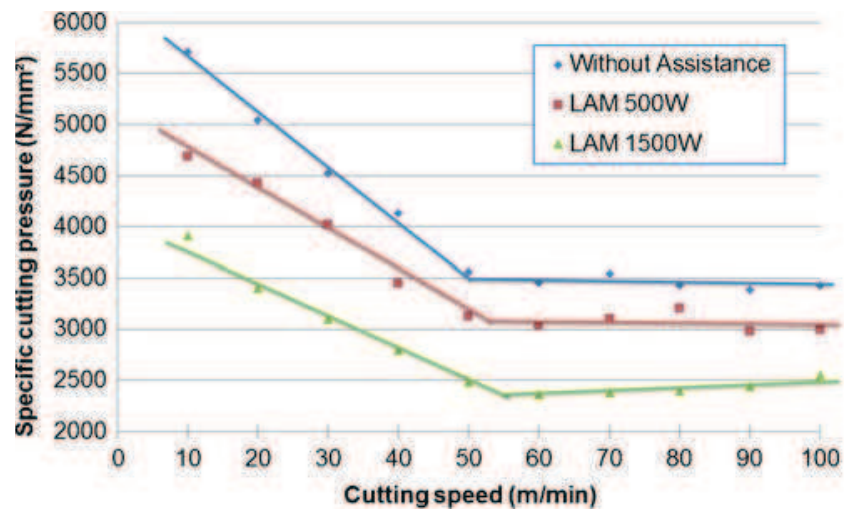

Fig. 3 Evolution of the specific cutting pressure as a function of the laser power and cutting speed 
Fig. 4 Influence of laser power on the cutting force for a different depths of cut $(f=0.15 \mathrm{~mm} / \mathrm{rev})$ and $\mathbf{b}$ different feeds $\left(a_{\mathrm{p}}=0.5 \mathrm{~mm}\right)$. $V_{\mathrm{c}}=50 \mathrm{~m} / \mathrm{min}$ a

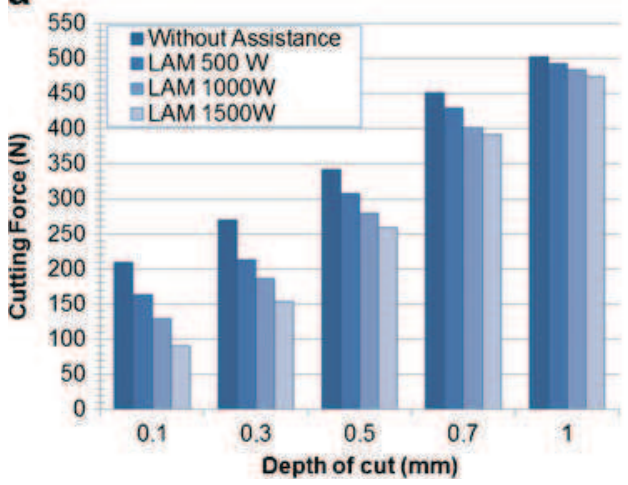

b

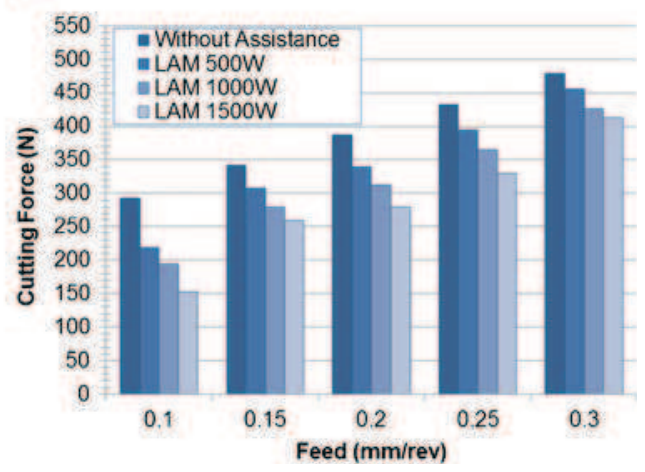

T500 ${ }^{\circledR}$ roughness meter. In this study, the arithmetic mean surface roughness, $R_{\mathrm{a}}$ (in micrometer), and the total height of roughness profile, $R_{\mathrm{t}}$ (in micrometer), were studied. Figure 5 shows the values of $R_{\mathrm{a}}$ and $R_{\mathrm{t}}$ for a feed of $0.2 \mathrm{~mm} / \mathrm{rev}$ and a cutting depth of $0.5 \mathrm{~mm}$. For these test conditions, regardless of the cutting speed, the laser power has no influence on the $R_{\mathrm{a}}$ and $R_{\mathrm{t}}$ roughness values. For cutting speeds below $30 \mathrm{~m} / \mathrm{min}$, the influence of the cutting speed on the surface roughness $R_{\mathrm{t}}$ is very pronounced. When the cutting speed goes from 10 to $30 \mathrm{~m} / \mathrm{min}$, the $R_{\mathrm{t}}$ roughness goes from 3.20 to $2.40 \mu \mathrm{m}$. Beyond a cutting speed of $30 \mathrm{~m} / \mathrm{min}$, the $R_{\mathrm{t}}$ roughness appears to decrease more slowly. It goes from $R_{\mathrm{t}}=2.40$ to $1.90 \mu \mathrm{m}$, when the cutting speed goes from 30 to $100 \mathrm{~m} / \mathrm{min}$. The $R_{\mathrm{a}}$ roughness decreases slowly and linearly from 0.66 to $0.45 \mu \mathrm{m}$ when the cutting speed goes from 10 to $100 \mathrm{~m} / \mathrm{min}$. The surface roughness is not affected by laser assistance.

Additional tests have been done for a fixed cutting speed of $50 \mathrm{~m} / \mathrm{min}$. The cutting depth is initially set at $0.5 \mathrm{~mm}$, and the feed is varied from 0.1 to $0.3 \mathrm{~mm} / \mathrm{rev}$. The feed is then set at $0.2 \mathrm{~mm} / \mathrm{rev}$, and the cutting depth is varied from 0.1 to $1 \mathrm{~mm}$. The two roughness criteria, $R_{\mathrm{a}}$ and $R_{\mathrm{t}}$, evolve in much the same way; therefore, only the $R_{\mathrm{a}}$ criterion is discussed below. Figure 6 shows the evolution of the $R_{\mathrm{a}}$ roughness as a function of the laser power for these feeds and different

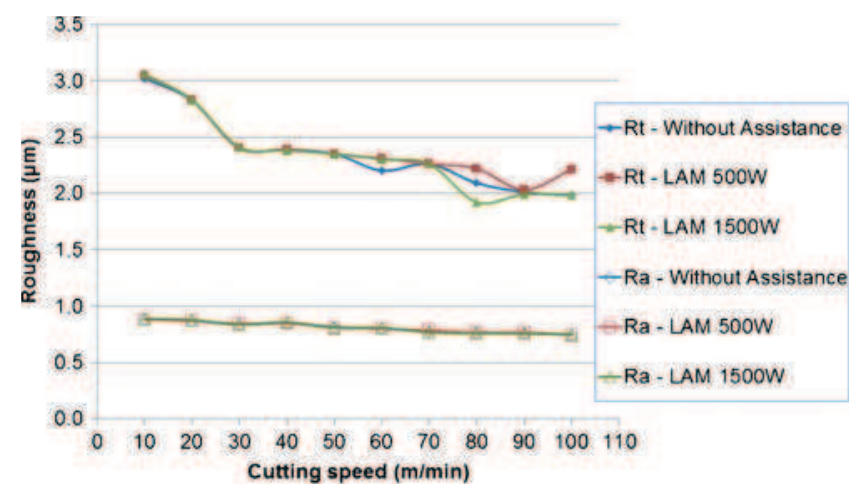

Fig. $5 R_{\mathrm{a}}$ and $R_{\mathrm{t}}$ roughness as a function of the cutting speed for different laser powers $\left(f=0.2 \mathrm{~mm} / \mathrm{rev}, a_{\mathrm{p}}=0.5 \mathrm{~mm}\right)$ cutting depths. The $R_{\mathrm{a}}$ roughness criterion tends to increase with increasing laser power for low feeds $(0.1$ and $0.15 \mathrm{~mm} / \mathrm{rev})$. However, the roughness tends to decrease with increasing laser power for the highest feeds $(>0.2 \mathrm{~mm} / \mathrm{rev}$ ) except for the maximum laser power. The results observed for the maximum laser power are related to thermal degradation of the tool by reflection of the laser beam. Indeed, part of it is reflected onto the tool insert which is heated and wears more rapidly. This degradation has been observed in other alloys [14].

It can be seen in Fig. $6 \mathrm{~b}$ that the average roughness increases very slightly with the cutting depth to a quasistable value of $0.92 \mu \mathrm{m}$ at a cutting depth of $0.5 \mathrm{~mm}$. Moreover, it is noted that for these test conditions (feed, $0.2 \mathrm{~mm} / \mathrm{rev}$; cutting speed, $50 \mathrm{~mm} / \mathrm{min}$ ), the average roughness is not influenced by laser power, especially for the highest cutting depths. This is not the case for a cutting depth of $0.1 \mathrm{~mm}$ for which the roughness deteriorates rapidly for a power of $1,500 \mathrm{~W}$. In this configuration, there is an effect of surface tearing, which is associated with high temperatures obtained in the material causing an increase in ductility.

Globally, regardless of the cutting speed, feed, or cutting depth, the laser assistance has little influence on $R_{\mathrm{a}}$ and $R_{\mathrm{t}}$ roughnesses. The only visible differences are for low feeds when the tool may deteriorate due to reflection of the laser or at low cutting depths when tearing of the material may occur due to overheating. These results are less definitive than those of Baili et al. [4] who found for the same alloy, machined with induction heating assistance, a net decrease of the roughness with increasing temperature of the workpiece. The results are also not in agreement with those of Dandekar et al. [21] who observed a decrease in roughness with increasing surface temperature for the laser-assisted machining of the Ti-6Al-4V alloy.

\subsubsection{Residual stresses and strain hardening}

Figure 7 shows, for a cutting speed of $50 \mathrm{~m} / \mathrm{min}$, a feed of $0.15 \mathrm{~mm} / \mathrm{rev}$ and a cutting depth of $0.5 \mathrm{~mm}$, residual stresses 
Fig. 6 Influence of the laser power on the arithmetic mean surface roughness for a different feeds $\left(a_{\mathrm{p}}=0.5 \mathrm{~mm}\right)$ and $\mathbf{b}$ for different depths of cut $(f=0.2 \mathrm{~mm} / \mathrm{rev})-V_{\mathrm{c}}=50 \mathrm{~m} / \mathrm{min}$ a

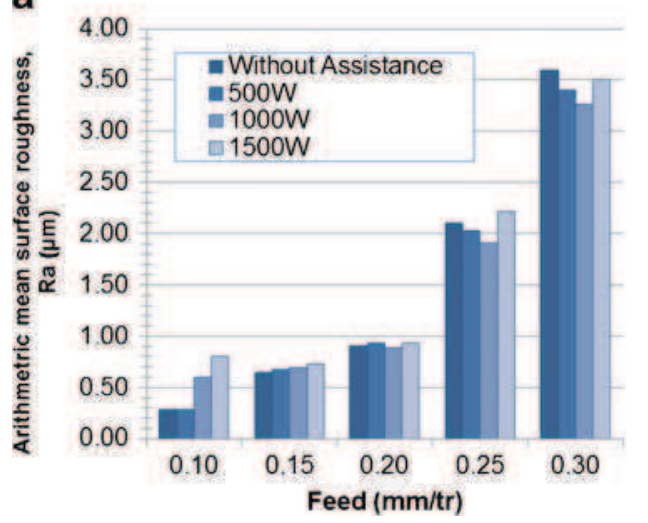

b

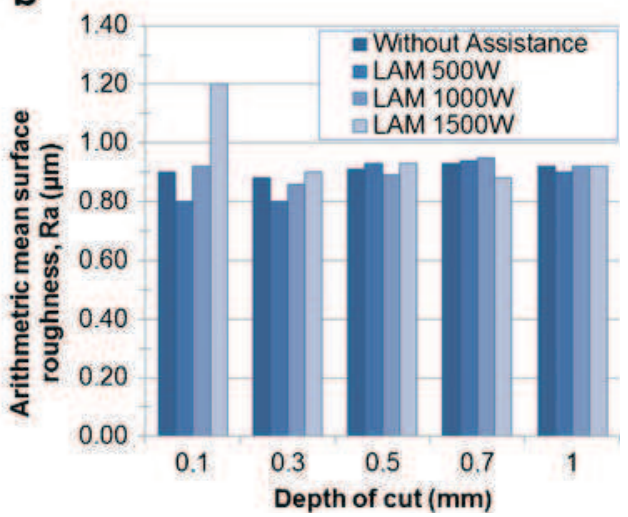

depth profiles determined in the axial and circumferential directions for conventional machining tests and two laserassisted machining tests with laser power of 500 and $1,500 \mathrm{~W}$, respectively.

The surface residual stresses in both directions are all compressive except those resulting from the laser-assisted machining test at $1,500 \mathrm{~W}$. In fact, it is important to note that the greater the laser power, the greater these surface stresses tend towards positive or tensile stresses. The circumferential surface stress goes from $-550 \mathrm{MPa}$ for conventional machining to $+400 \mathrm{MPa}$ for the laserassisted machining test with a laser power of $1,500 \mathrm{~W}$. Indeed, as found for other alloys [14], higher workpiece surface temperatures result in tensile residual stresses. Laser heating causes an increase in the surface temperature which generates, via thermal expansion of the surface layer, high compressive stresses. After cooling, the thermal shock leads to residual tensile stresses in this layer. However, the depth affected by the residual stress is only slightly influenced by the laser power.

The surface diffraction peak width, which characterizes the level of strain hardening of the material, decreases strongly with increasing laser assistance (Fig. 8). The hardening of the material is therefore less important for laserassisted machining. Moreover, the strain hardening-affected depth tends to decrease with increasing laser power $(30 \mu \mathrm{m}$ at $1,500 \mathrm{~W}$ compared to $75 \mu \mathrm{m}$ without assistance). The influence of temperature is much higher than in the surface layer due to the very poor thermal conductivity and high strain localization of the titanium alloy [7].

This study was completed with the analysis of other residual stress profiles performed on machined surfaces with a higher cutting speed of $100 \mathrm{~m} / \mathrm{min}$ (Fig. 9). It can be seen that the effects of laser power remain the same but with lower intensity. Indeed, for a cutting speed of $50 \mathrm{~m} / \mathrm{min}$, the circumferential surface residual stress increases to $930 \mathrm{MPa}$ with increasing laser power from 0 to $1,500 \mathrm{~W}$, whereas for a cutting speed of $100 \mathrm{~m} / \mathrm{min}$, this increase is only $220 \mathrm{MPa}$.

As per the tests performed at a cutting speed of $50 \mathrm{~m} / \mathrm{min}$, the peak width decreases as the temperature increases due to laser heating (Fig. 10). It goes from $4.6^{\circ}$ for conventional machining to $3.8^{\circ}$ for laser-assisted machining with a power of $1,500 \mathrm{~W}$, which corresponds to a decrease of $17 \%$. This decrease is lower than for a speed of $50 \mathrm{~m} / \mathrm{min}$ for which laser assistance causes a decrease of $31 \%$ of the peak width.

The results of this study on the Ti555-3 alloy are consistent with those available for the Ti6Al4V alloy in terms of residual stresses [14]. In this titanium alloy, the surface
Fig. 7 Residual stress as a function of depth for different laser powers $\left(a_{\mathrm{p}}=0.5 \mathrm{~mm}\right.$, $f=0.15 \mathrm{~mm} / \mathrm{rev}, V_{\mathrm{c}}=50 \mathrm{~m} / \mathrm{min}$ )
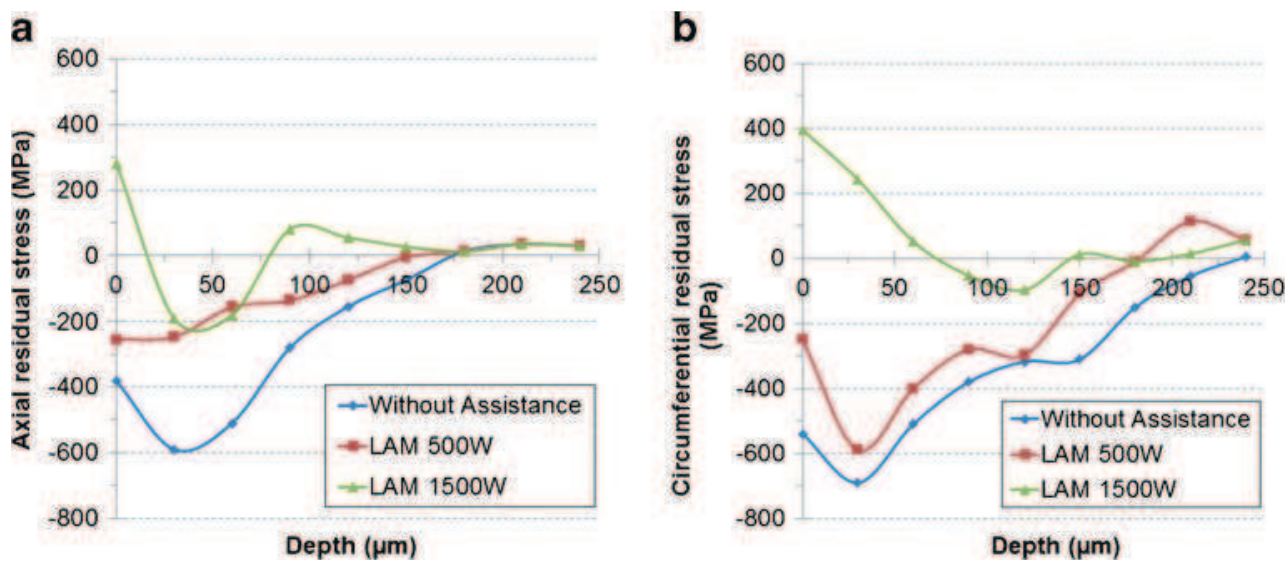


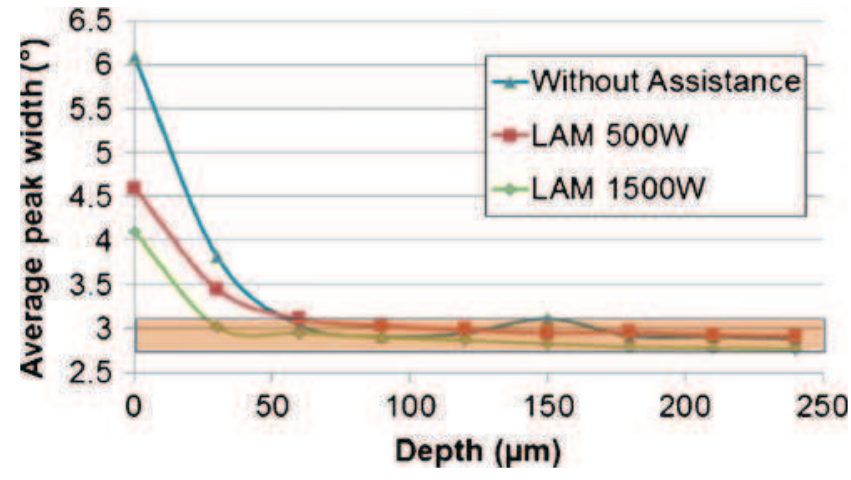

Fig. 8 Average peak width as a function of depth for different laser powers $\left(a_{\mathrm{p}}=0.5 \mathrm{~mm}, f=0.15, V_{\mathrm{c}}=50 \mathrm{~m} / \mathrm{min}\right)$

residual stresses were also seen to increase (towards positive tensile stresses) when the laser power increases. This trend is even more marked when the cutting speed is low. Indeed, when the cutting speed decreases, the surface temperature increases and thermal effects are more influential. Figure 11 compares the circumferential surface residual stresses obtained for the Ti555-3 alloy and the Ti6Al4V alloy under very similar test conditions $\left(a_{\mathrm{p}}=0.5 \mathrm{~mm}, f=0.15 \mathrm{~mm} / \mathrm{rev}\right.$, $V_{\mathrm{c}}=50 \mathrm{~m} / \mathrm{min}$ for the Ti555-3 alloy and $a_{\mathrm{p}}=0.5 \mathrm{~mm}$, $f=0.10 \mathrm{~mm} / \mathrm{rev}, V_{\mathrm{c}}=54 \mathrm{~m} / \mathrm{min}$ for the Ti6Al4V alloy). The trends are the same for the axial surface residual stresses. It is found that the Ti555-3 alloy, machined without assistance, has more compressive surface residual stresses than the Ti6Al4V alloy. However, the compressive stresses increase more quickly to tensile stresses with increasing laser power compared to those measured in the Ti6Al4V alloy.

\subsection{Influence of laser assistance on chip morphology}

During chip formation, the material undergoes intense plastic deformation at high strain rates, following a relatively complex loading path. Micrographic observation of chip morphologies can provide information concerning the

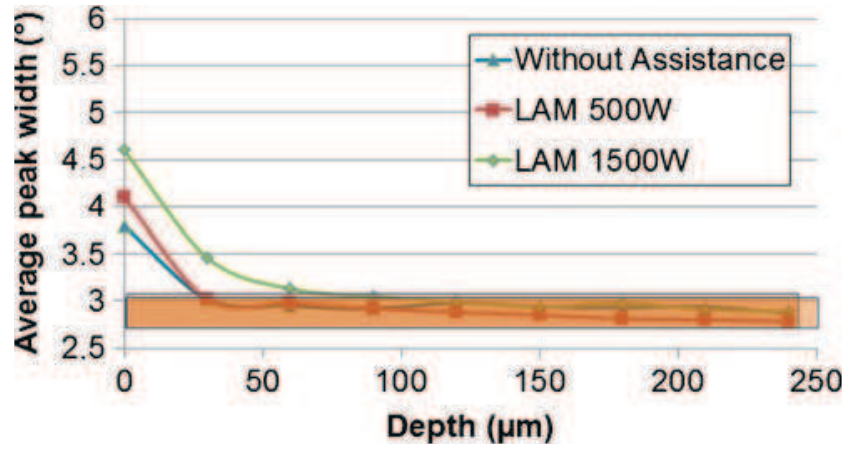

Fig. 10 Average peak width as a function of depth for different laser powers $\left(a_{\mathrm{p}}=0.5 \mathrm{~mm}, f=0.15 \mathrm{~mm} / \mathrm{rev}, V_{\mathrm{c}}=100 \mathrm{~m} / \mathrm{min}\right)$

mechanisms of material flow during chip formation. Adding laser assistance can affect these mechanisms. Additional orthogonal cutting tests were performed with a CP500 (Seco $\left.{ }^{\circledR}\right)$ tool with a TiAlN + TiN surface coating, in order to obtain further information concerning the mechanisms of chip formation. Figure 12 shows different chip morphologies obtained during convention machining tests on the Ti555-3 alloy. The cutting speed is fixed at $50 \mathrm{~mm} / \mathrm{min}$ and the feed is varied. For a low feed $(0.05 \mathrm{~mm} / \mathrm{rev})$, the chips exhibit a low level of discontinuity. The deformation is relatively uniform. When the feed is increased, the chips have a more discrete form, and bands of intense deformation are formed. The mechanism by which these bands are formed is strongly related to the mechanical and thermo-physical properties of the material. It is attributed to a phenomenon of strain localization in the primary shear zone, which is favored by the low thermal conductivity of the material.

Figure 13 shows a closer examination of the shear zones, in which occur the white bands in the primary and secondary shear zones. It is somewhat surprising to find these white bands in the Ti555-3 titanium alloy as they were not observed in the Ti6Al4V alloy [11]. However, they were observed by several authors in the machining of hard steels,
Fig. 9 Laser-assisted machining residual stress profiles $\left(a_{\mathrm{p}}=0.5 \mathrm{~mm}, f=\right.$ $\left.0.15 \mathrm{~mm} / \mathrm{rev}, V_{\mathrm{c}}=100 \mathrm{~m} / \mathrm{min}\right)$ a

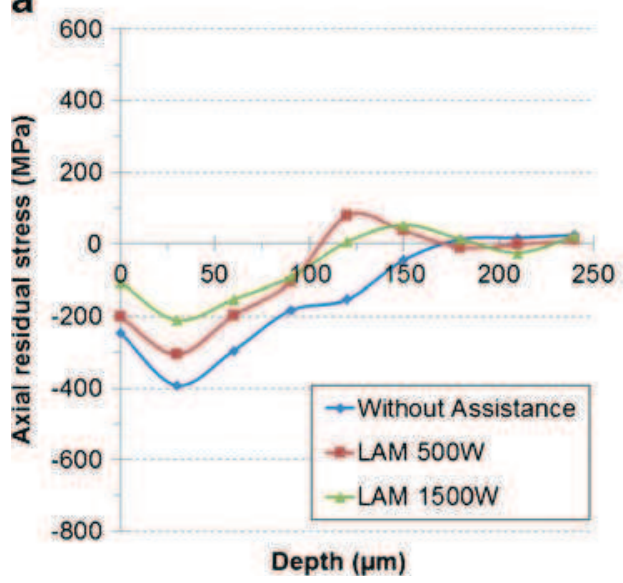

b

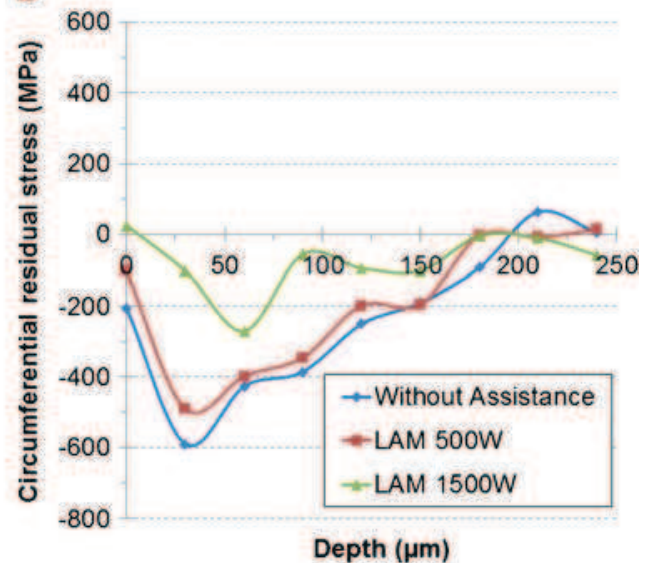




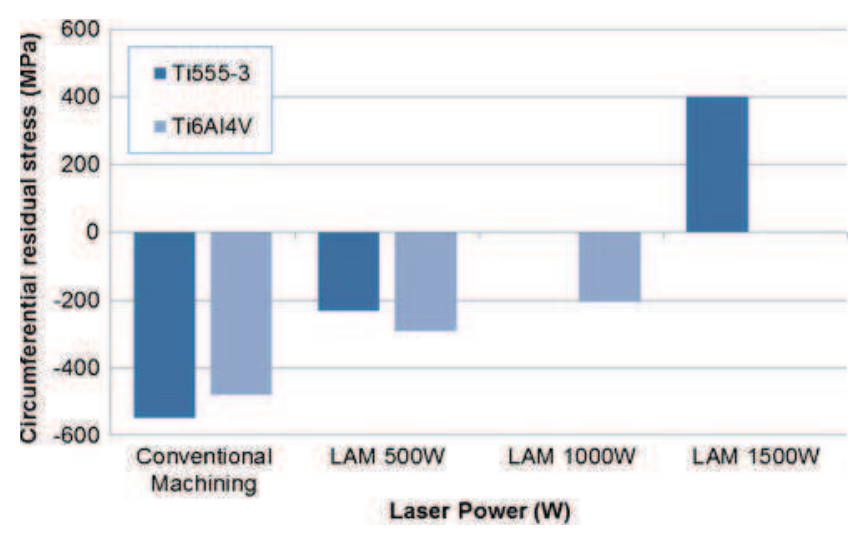

Fig. 11 Comparison of the circumferential surface residual stresses obtained in the Ti555-3 alloy and the Ti6A14V alloy [14] for similar test conditions

such as Ramesh et al. [22]. These authors concluded that these bands appear after a sharp rise in temperature and/or intense plastic deformation.

The analysis of the experimental work shows that the number of white bands increases with increasing values of the cutting parameters and particularly with increasing cutting speed. The temperatures induced in the different shear zones rise strongly when the cutting speed increases [9]. This promotes the formation of white bands via thermal effects. The observed white bands have a linear form similar to the form observed by Habak for the $100 \mathrm{Cr} 6$ steel with carbide [23].

Figure 14 shows a comparison between a conventional machining test and a laser-assisted machining test with a laser power of $1,500 \mathrm{~W}$, in terms of the chip morphology formed during a machining operation (cutting speed of $50 \mathrm{~m} / \mathrm{min}$ and feed of $0.15 \mathrm{~mm} / \mathrm{rev}$ ).

Laser-assisted machining results in chips that are very different from those resulting from conventional machining. It can be seen from the two micrographs in Fig. 14 that the chips formed by laser-assisted machining appear more continuous because the sawtooth frequency is much greater. Indeed, many white bands are observed which allow slip bands to occur between each sawtooth.

4.4 Analysis on chip formation in laser-assisted machining of the Ti555-3 alloy

Chip formation in conventional as in laser-assisted machining is mainly governed by the shear zones: the primary zone (shearing causing the chip formation), the secondary zone (shearing due to friction between the chip and the rake face of the tool) and tertiary zone (shearing due to friction between the generated surface and the flank face of the tool).
Fig. 12 Chip morphology as a function of the feed (Ti555-3, Tool CP500, $V_{\mathrm{c}}=50 \mathrm{~mm} / \mathrm{min}$, no laser assistance)

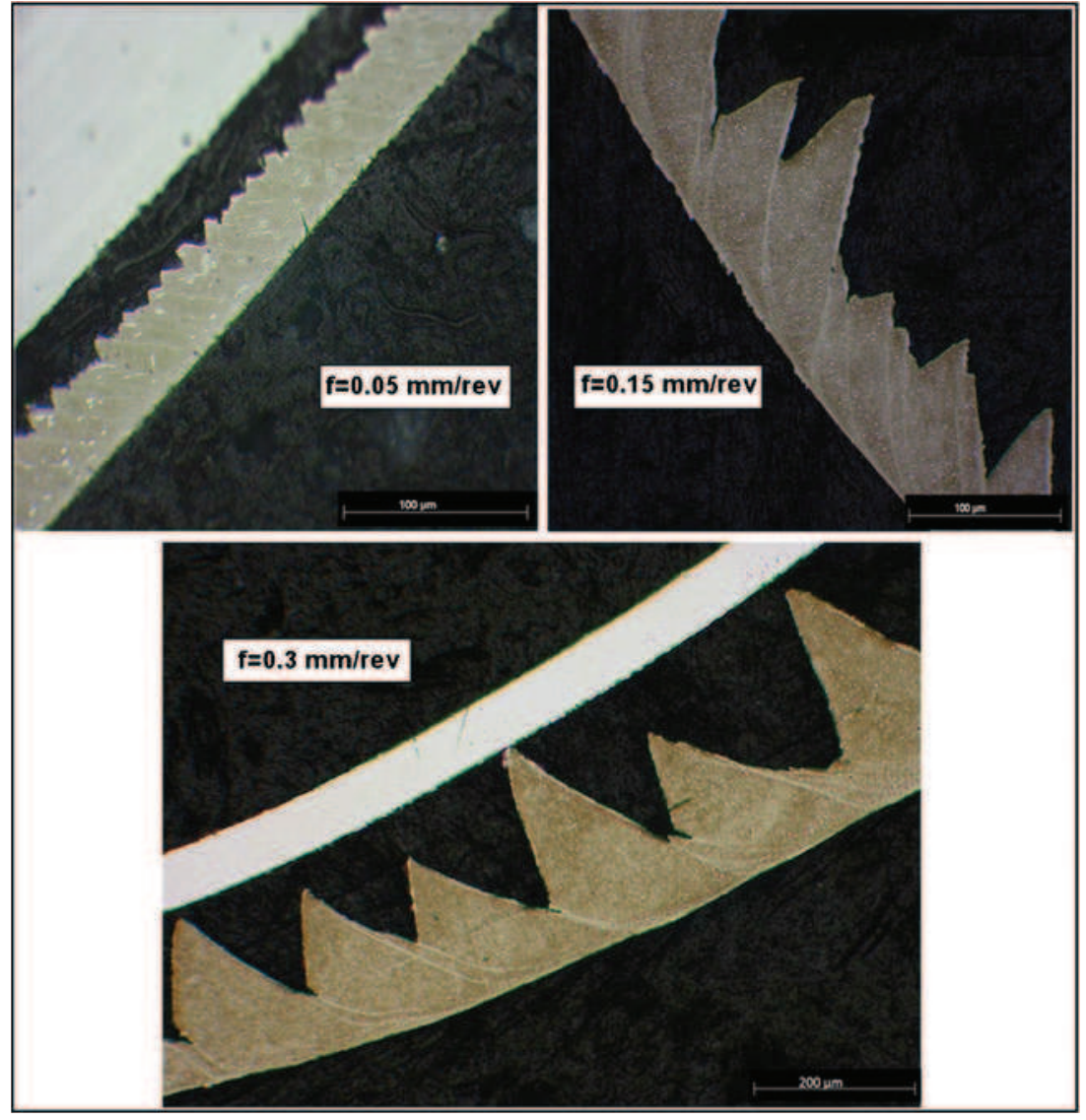


Fig. 13 Observation of white bands in zones I and II (Tool CP500, $V_{\mathrm{c}}=90 \mathrm{~m} / \mathrm{min}$, $f=0.15 \mathrm{~mm} / \mathrm{rev}$

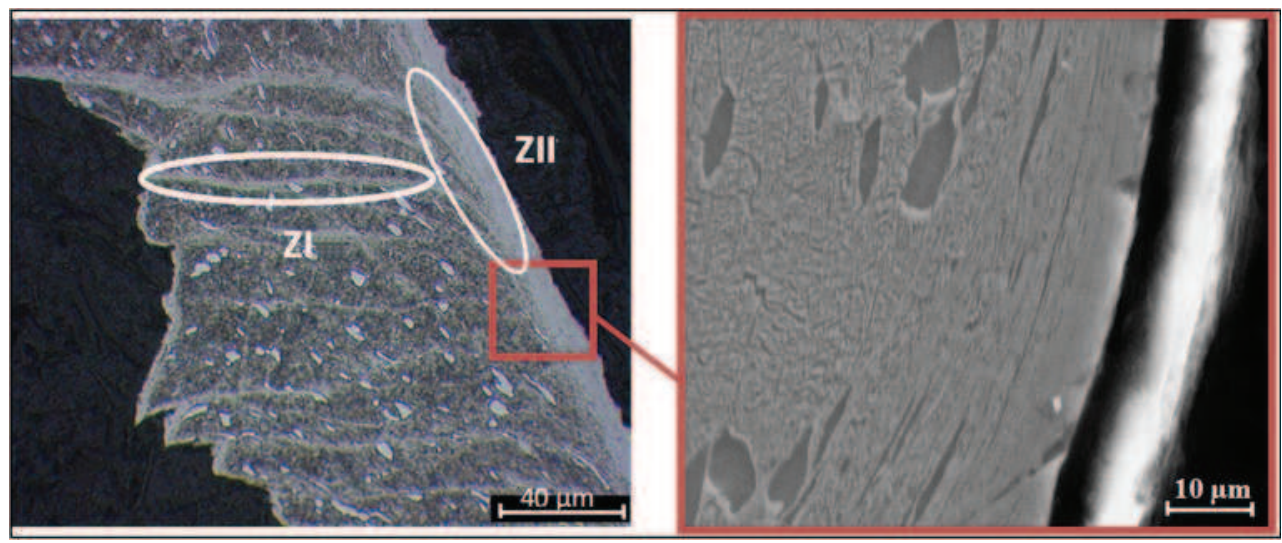

The temperature increase induced by laser modifies the shear zone's characteristics which results in evolution of chip morphology, cutting forces, and residual stresses, as shown in the previous parts.

Discontinuous chips with a great number of sawteeth of small heights were observed in the Ti555-3 alloy machined with laser assistance (Fig. 14). Contrary to the results of Lesourd [19], the strain in the chip due to the primary shear zone is not homogeneous in laser-assisted machining, which is the case for a continuous chip, but it is discontinuous with numerous slip bands. In both cases, the overall appearance of the chip is continuous, but the formation mechanisms are totally different. The increased sawtooth frequency can be explained by the increase in temperature with laser assistance. In conventional machining, the tool must accumulate enough material on the rake face so that the stress increases in the primary shear zone to the flow stress and thus causes the slip that allows the creation of the sawtooth. In laser assistance, the preheated material has a lower flow stress. Therefore, it takes less build-up of material on the rake face to cause the appearance of the sawtooth. The sawteeth are therefore formed with greater frequency.

Besides, numerical studies [11] have shown that in the secondary shear zone, laser assistance generates a compressive stress field normal to the contact surface between the tool and the chip lower than the stress field observed in conventional machining. Lower stress in this zone, situated behind the cutting edge, associated to less important flow stress, can explain the decrease of the cutting force measured with laser assistance.

The tertiary shear zone, which corresponds to the tool/workpiece surface contact, is smaller in size than the previous ones, but has a strong influence on the surface integrity of the workpiece, in particular on the creation of residual stresses. This tertiary shear zone is modified, in particular if the depth of the laser-heated zone is greater than the cutting depth. In that case, some of the thermal energy provided by the laser is not removed by machining, which results in an increase of the surface temperature of the workpiece. It is well known that residual stresses result from an incompatibility between a surface layer and the bulk material. As explained by Dogra et al. [24], the mechanical effect of the cutting tool sliding across the workpiece leads to tensile plastic deformation in the surface layer which generates compressive residual stresses after the cutting process. At the same time, the thermal effect, mainly due to the friction in the tertiary shear band, expands the surface layer producing compressive stresses, which become tensile residual stresses after cooling. Laser heating acts both on mechanical and thermal effects. It causes a thermal softening of the workpiece inducing lower mechanical effects. Besides, the increase of the surface temperature generates an unwanted thermal expansion, resulting in higher thermal effects. As a consequence, laser power increases the surface residual stresses towards positive tensile stresses as shown on Figs. 7 and 9.
Fig. 14 Comparison between chips formed in a conventional machining and $\mathbf{b}$ laser-assisted machining

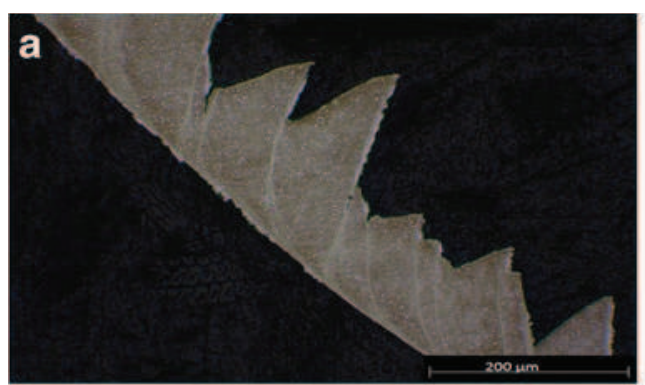

Conventional Machining

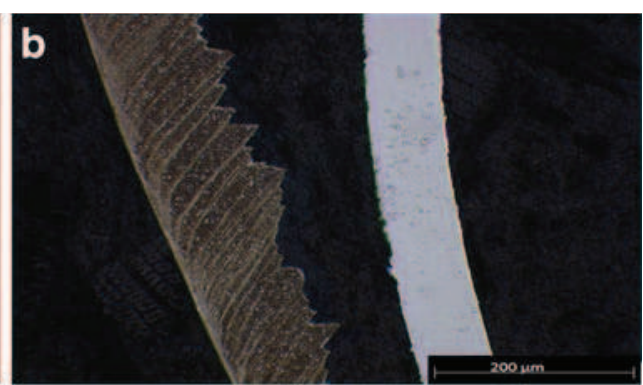

LAM 1500W 


\section{Conclusions}

The results of this study highlight the poor machinability of the Ti555-3 titanium alloy, which is characterized by a minimum cutting speed of $50 \mathrm{~m} / \mathrm{min}$ and high cutting forces.

The use of laser assistance leads to the following conclusions:

1. There is a significant decrease in the cutting force. This decrease is more important when the surface temperature is high. The surface temperature depends strongly on the cutting parameters. It increases if the cutting depth, the feed, and the cutting speed decrease.

2. The surface roughness is almost unaffected by laser assistance.

3. The residual stresses tend towards tensile stress with the increase in laser power. The strain hardening, in turn, decreases in intensity and depth.

4. The chip sawtooth frequency increases with laser power. Hence, the chips resemble a continuous chip, despite the very different formation mechanism.

5. There is, with or without laser assistance, the appearance of white bands in shear zones of the chips. These white zones are characteristics of a high temperature rise and/or intense plastic deformation and were not observed in the Ti6Al4V titanium alloy.

\section{References}

1. Arrazola P, Garay A, Iriarte L, Armendia M, Marya S, Le Maître F (2009) Machinability of titanium alloys (Ti6Al4V and Ti555.3). J Mater Process Technol 209(5):2223-2230. doi:10.1016/ j.jmatprotec.2008.06.020

2. López De Lacalle LN, Pérez-Bilbatua J, Sánchez JA, Llorente JI, Gutiérrez A, Albóniga J (2000) Using high pressure coolant in the drilling and turning of low machinability alloys. Int J Adv Manuf Technol 16(2):85-91

3. Hong SY, Markus I, Jeong W (2001) New cooling approach and tool life improvement in cryogenic machining of titanium alloy Ti6Al-4 V. Int J Mach Tools Manuf 41(15):2245-2260. doi:10.1016 S0890-6955(01)00041-4

4. Baili M, Wagner V, Dessein G, Sallaberry J, Lallement D (2011) An experimental investigation of hot machining with induction to improve Ti-5553 machinability. Appl Mech Mater 62:67-76. doi:10.4028/www.scientific.net/AMM.62.67

5. Sun S, Brandt M, Dargusch MS (2010) The effect of a laser beam on chip formation during machining of Ti6A14V alloy. Metall Mat Trans A Phys Metall Mat Sci 41(6):1573-1581

6. Ezugwu EO, Wang ZM (1997) Titanium alloys and their machinability-a review. J Mater Process Technol 68(3):262-274. doi:10.1016/S0924-0136(96)00030-1
7. Sun S, Brandt M, Dargusch MS (2010) Thermally enhanced machining of hard-to-machine materials - a review. Int J Mach Tools Manuf 50(8):663-680

8. Ezugwu EO, Bonney J, Yamane Y (2003) An overview of the machinability of aeroengine alloys. J Mater Process Technol 134(2):233-253. doi:10.1016/S0924-0136(02)01042-7

9. Wagner V, Baili M, Dessein G, Lallement D (2011) Experimental study of coated carbide tools behaviour: application for Ti-5-5-5-3 turning. Int J Mach Mach Mater 9(3-4):233-248

10. Braham-Bouchnak T (2010) Etude du comportement en sollicitations extrêmes et de l'usinabilité d'un nouvel alliage de titane aéronautique: le Ti555-3. PhD Thesis, Arts et MétiersParisTech. http://pastel.archives-ouvertes.fr/pastel-00560093

11. Germain G, Dal Santo P, Lebrun JL (2011) Comprehension of chip formation in laser assisted machining. Int $\mathrm{J}$ Mach Tools Manuf 51(3):230-238. doi:10.1016/j.jimachtools.2010.11.006

12. Leshock CE, Kim J, Shin YC (2001) Plasma enhanced machining of Inconel 718: modeling of workpiece temperature with plasma heating and experimental results. Int $\mathrm{J}$ Mach Tools Manuf 41(6):877-897. doi:10.1016/S0890-6955(00)00106-1

13. López De Lacalle LN, Sánchez JA, Lamikiz A, Celaya A (2004) Plasma assisted milling of heat-resistant superalloys. J Manuf Sci Eng Trans ASME 126(2):274-285

14. Germain G, Morel F, Lebrun J, Morel A (2007) Machinability and surface integrity for a bearing steel and a titanium alloy in laser assisted machining (optimisation on LAM on two materials). Lasers Eng 17(5-6):329-344

15. François M, Sprauel JM, Déhan CF, James MR, Convert F, Lu J, Lebrun JL, Ji N, Hendrics RW (1996) X-ray diffraction method. Handbook of measurement of residual stresses, pp 71-131

16. AFNOR Norm NF E66-520 (2008) Working zones of cutting tools -couple tool-material, part 1 to 8

17. Arrazola PJ, Villar A, Ugarte D, Marya S (2007) Serrated chip prediction in finite element modeling of the chip formation process. Mach Sci Technol 11(3):367-390. doi:10.1080/ 10910340701539882

18. Germain G (2006) Contribution à l'optimisation du procédé d'usinage assisté laser. Ph D Thesis, ENSAM. http:// pastel.archives-ouvertes.fr/pastel-00002127

19. Lesourd B (1996) Etude et modélisation des mécanismes de formation de bandes de cisaillement intense en coupe des métaux. Application au tournage assisté laser de l'alliage de Titane TA6V. PhD Thesis, ED 82-174, Ecole Centrale de Nantes

20. Rajagopal S, Plankenhorn DJ, Hill VL (1982) Machining aerospace alloys with the aid of a $15 \mathrm{~kW}$ laser. J Appl Metalwork 2(3):170-174

21. Dandekar CR, Shin YC, Barnes J (2010) Machinability improvement of titanium alloy (Ti-6Al-4 V) via LAM and hybrid machining. Int J Mach Tools Manuf 50(2):174-182. doi:10.1016/ j.ijmachtools.2009.10.013

22. Ramesh A, Melkote SN, Allard LF, Riester L, Watkins TR (2005) Analysis of white layers formed in hard turning of AISI 52100 steel. Mater Sci Eng, A 390(1-2):88-97

23. Habak M, Lebrun J-L, Morel A (2007) A study of the influence of the metallurgical state on shear band and white layer generation in $100 \mathrm{Cr} 6$ steel: application to machining. AIP Conference Proceedings 907:691-696

24. Dogra M, Sharma VS, Sachdeva A, Suri NM, Dhiman S (2012) Surface integrity a key issue in hard turning - a review. Int J Mach Mach Mater 12(1-2):88-116 